\author{
VERSIT^ 10.2478/auoc-2013-0017 \\ Ovidius University Annals of Chemistry \\ Volume 24, Number 2, pp. 98-108, 2013
}

\title{
Ensuring security of local gas supply using pipeline gas storage
}

\author{
Cristian EPARU*a $*^{\mathrm{a}}$, Silvian SUDITU ${ }^{\mathrm{a}}$ and Alina PRUNDUREL ${ }^{\mathrm{a}}$ \\ ${ }^{a}$ Department of Drilling, Extraction and Transport of Hydrocarbons, \\ Petroleum - Gas University of Ploiesti
}

\begin{abstract}
This paper presents a natural gas supply system of a locality. Since power consumption is nonstationary, for supplying the consumption peaks it is used a gas deposit kept in a pipeline built near the locality. The viability of this solution was demonstrated by simulation with the numerical simulator SIMONE.
\end{abstract}

Keywords: gas, pipeline, storage, consumption

\section{Introduction}

Most of the industrial facilities are connected to distribution networks located in urban areas. They also supply in the same time other categories of consumers. The consumption of gas is defined by the needs of the customers varying more or less during a day, or from a season to another, depending mainly on the temperature and on the day of the week. The total flow of a distribution network is made up of a basic flow , correspondent to industrial users who have an individual consumption level which depends on the type of industry to which it belongs, over which a variable consumption flow is superimposed in inverse ratio to temperature. The overlap of all these effects determines for the gas distribution company an irregular consumption with peaks and periods of low consumption.

For this reason, at all city gates from the gas carrier/transporter to the gas distribution networks, there is both a time fluctuation of gas consumption during the same day and a seasonal fluctuation of these consumptions. About half the gas consumption has a variable condition influenced by climatic factors (temperature, wind, precipitation). Creating new production and transportation possibilities only to ensure the gas yield surplus for a short period, cannot constitute an acceptable economical solution. A solution to compensate consumption peaks is to develop gas storage directly in the transportation pipelines or in pipes designed specifically for this purpose. Storage of the gas in the pipeline can be made during periods of minimal consumption, when the nominal output exceeds the gas yield in use, the pipeline pressure reaching a maximum value. This operation loses its intensity when during the rate of the flow delivered/supplied to consumers is higher than the nominal transportation flow/output of the pipe and completely ceases when it reaches the maximal consumption peaks, then the pressure in the pipe tends to a minimum. Gas distribution companies, according to the Network Code, must submit to the transporter the necessary quantities of gas for the customers, along with daily consumption profile. Consumption profiles are functions built by the gas distributor based on which daily evaluations can be made, depending on the temperature forecast of the required gas. Any difference of more than $2 \%$ between the forecasted consumption and the real one is penalized.

Figure 1 shows the profile of natural gas consumption for one year and the one realized on the basis of temperature variation and daily balance.

To avoid penalties for not complying with the amount of gas supply in the contract, storage pipelines can be built for gas storage. This quantity of gas can be used to balance the differences between estimated volumes and the real ones. Besides the storage pipeline, a gas reduction plant is necessary. 


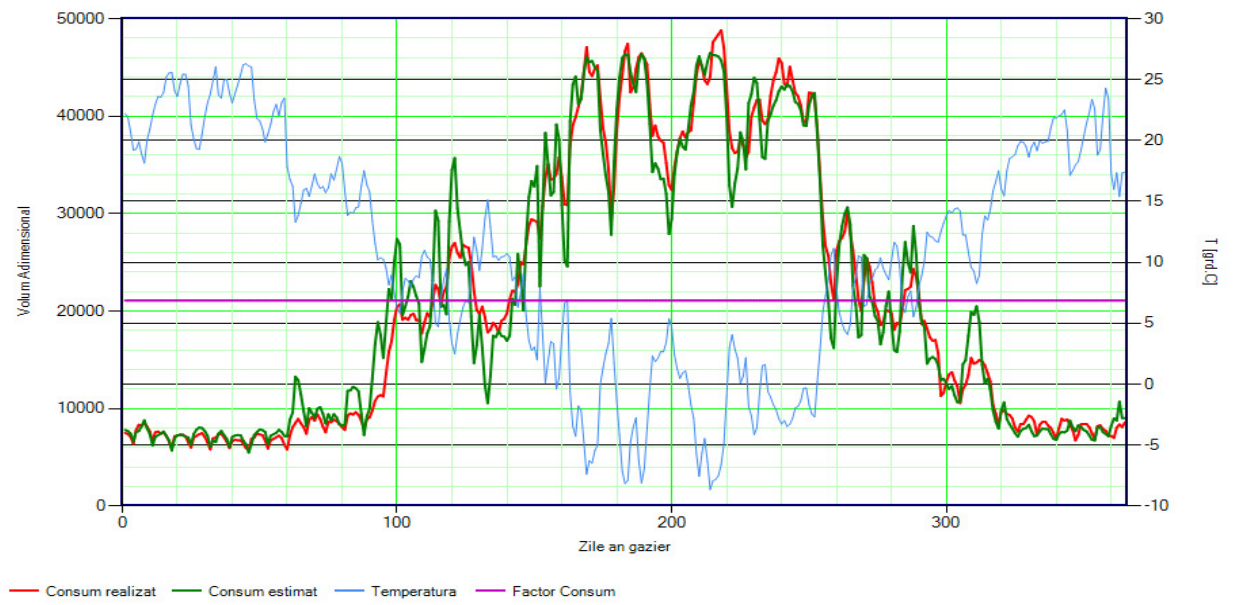

Fig.1 Sectional/Profiled consumption for a certain category of gas consumers

\section{Presentation of the solution for gas storage within a pipeline, to balance peak loads}

The solution for gas storage in the pipe was studied by creating a model using SIMONE simulator. The model is formed by the gas pipe which supplies a large consumer such as a city, four pipelines for gas storage, a gas controlling device to co-ordinate the taking-over of the gas from the storage pipeline and a reduction plant. The scenario reflects the situation in which during periods of minimal consumption the gas is stored in a pipe through a reduction station, so it can then be extracted when the gas consumption reach an hourly peak. For this we started from a distribution pipeline linking a SRM through which TRANSGAZ delivers gas to a distributor (e.g. GDF Suez) to a large consumer (City X) (Fig.2).

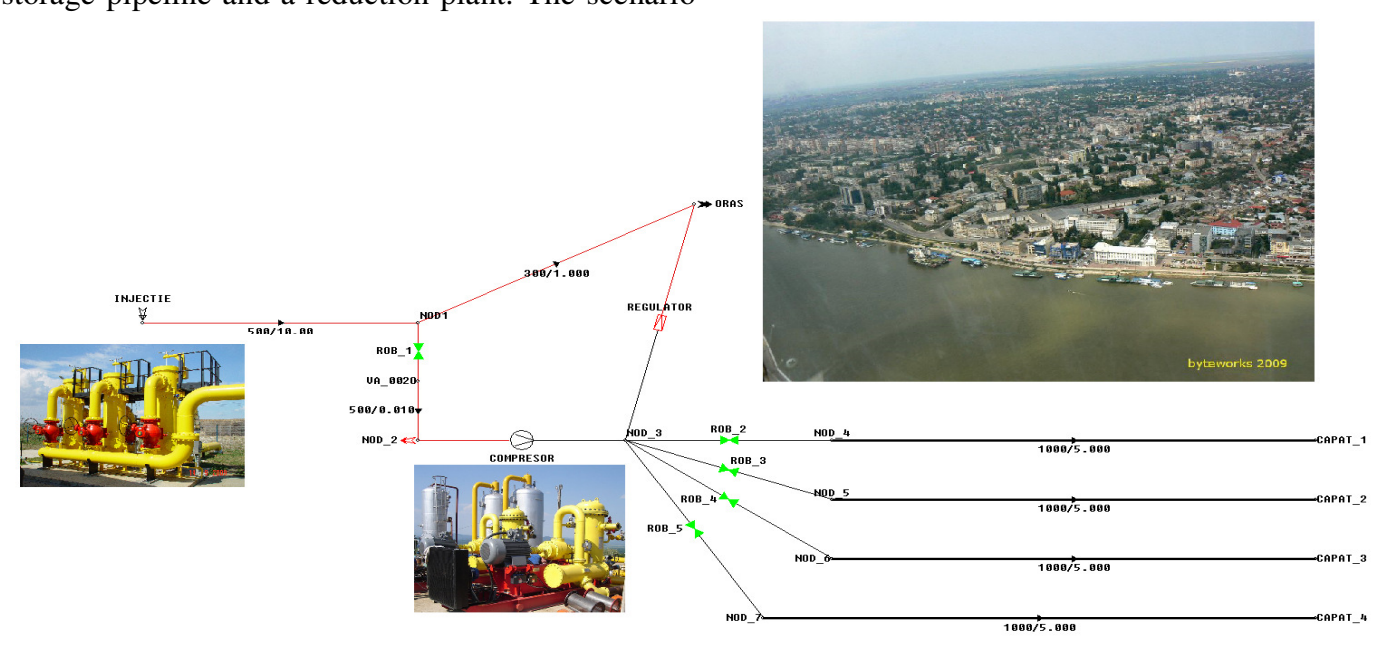

Fig.2 Scheme for gas storage in the pipeline, realized using SIMONE 


\section{Description of the simulation scenario}

The simulation was performed for a typical day in which the gas consumption was variable. In Fig. 3 you can see exactly how the system is operated/used, respectively the times when the controlling device/ regulator is programmed to open/start in order to meet the consumption peaks and when it is scheduled to start the compressor in order to restore pressure within the storage pipeline. To stop the compressor, a maximum value of the pressure in the storage pipe is disposed. When this value is achieved the compressor shuts down

The simulation was made taking into account the hourly consumption affected by the needs of each client, modeled through a consumption profile.
Table 1 presents the values of consumption profile based on time.

\section{The simulation results}

The simulation results show the viability of using the solution of gas storage in the pipeline to cover peak loads. As shown in the analysis of the results the reduction plant is operating intermittently to restore the supply of pipeline gas when the gas consumptions are low.

Figures 4 and $\mathbf{5}$ present the pressure variation and respectively the gas yield in the injection point in the distribution system represented by the SRM. One can easily see the irregularity of the flow as it enters the pipeline.

\begin{tabular}{|c|c|c|c|c|c|c|c|c|c|c|}
\hline \multicolumn{11}{|c|}{ Scentrio defintion } \\
\hline & Tme & & Condition & Objot & Type & Prameter & Vate & thas & Sourse & Corre \\
\hline & & & & ENJCTIE & NS Supply sode & PSET Set pressure & 3 & barg & & \\
\hline & & & & ORAS & No Node & Q Supply Otituke & $\mathrm{P} 1 \cdot 50$. & $1000 \mathrm{Nm}^{\prime} / \mathrm{s}$ & & \\
\hline & 0.00 & & & COMPRESOR & CS Coengressor station & SM Flow-rate setpoint & 40 & $1000 \mathrm{Nm}^{2} / \mathrm{h}$ & & \\
\hline & 0.00 & & & REGLLATOR & CV Control value & OFF Cose & & & & \\
\hline & 600 & & & COMPRESOR & CS Compretser station & Off Close & & & & \\
\hline & 600 & & & REGULATOR & CV Coestol valve & SPO Orque pressure setpoith & 4 & barg & & \\
\hline & 800 & & & ROB_1 & VA Vilve & ON Open & & & & \\
\hline & 1000 & & & REGULATOR & CV Control vale & OFF Close & & & & \\
\hline & 1000 & & & COMPRESOR & CS Compressor station & SM Flow-rate setpoint & 20 & $1000 \mathrm{Nm}^{2} / \mathrm{h}$ & & \\
\hline & 13.00 & & & CONQPESOR & CS Compressor station & OFF Close & & & & \\
\hline & 13,00 & & & REGULATOR & CV Conzol valve & SM Flow-rate setpoter & 15 & $1000 \mathrm{Nm}^{\prime} \mathrm{s}$ & & \\
\hline & 1400 & & & COMPRESOR & CS Compressor statica & SM Flow-rase setpoint & 15 & $1000 \mathrm{Nm}^{\prime} / \mathrm{s}$ & & \\
\hline & $14: 00$ & & & REGULATOR & CV Control value & OFF Cose & & & & \\
\hline & $15: 00$ & & & COMPRESOR & CS Compressor station & SM Flow-rate setpoint & 20 & $1000 \mathrm{Nm}^{1 / \mathrm{h}}$ & & \\
\hline & $17: 00$ & & & COMPRESOR & CS Congressor station & OFF Close & & & & \\
\hline & 1790 & & & REGLLATOR & CV Coesol valve & SM Flow-sane setpout & 10 & $1000 \mathrm{Nm}^{\prime} \mathrm{s}$ & & \\
\hline & 20000 & & & REGULATOR & CV Coestol value & SM Flow-rase setpoint & 15 & $1000 \mathrm{Nm}^{\prime} / \mathrm{t}$ & & \\
\hline & $21: 00$ & & & REGULATOR & CV Control value & SM Flow-rate setpoint & 20 & $1000 \mathrm{Nm} / \mathrm{h}$ & & \\
\hline & 23.00 & & & COMPRESOR & CS Compressor station & SM Flow-rate setpoint & 10 & $1000 \mathrm{Nm} / \mathrm{h}$ & & \\
\hline & $23: 00$ & & & REGTLATOR & CV Conzol value & OFF Close & & & & \\
\hline \multicolumn{11}{|c|}{$7 \cdot[\mathrm{D}$} \\
\hline Close & Rectaced & Fater & & & & & & & & \\
\hline
\end{tabular}

Fig.3 Working scenario for the simulation

Table 1 the values of consumption profile based on time.

\begin{tabular}{|l|l|l|l|l|l|l|l|l|l|l|l|l|l|}
\hline Hour & 0 & 1 & 2 & 3 & 4 & 5 & 6 & 7 & 8 & 9 & 10 & 11 & 12 \\
\hline Profile & 0.777 & 0.76 & 0.769 & 0.771 & 0.778 & 0.849 & 0.965 & 1.073 & 1.125 & 1.129 & 1.125 & 1.077 & 1.037 \\
\hline
\end{tabular}

\begin{tabular}{|l|l|l|l|l|l|l|l|l|l|l|l|l|}
\hline Hour & 13 & 14 & 15 & 16 & 17 & 18 & 19 & 20 & 21 & 22 & 23 & 24 \\
\hline Profile & 1.047 & 1.051 & 1.060 & 1.057 & 1.110 & 1.151 & 1.160 & 1.121 & 1.071 & 0.993 & 0.926 & 0.9 \\
\hline
\end{tabular}




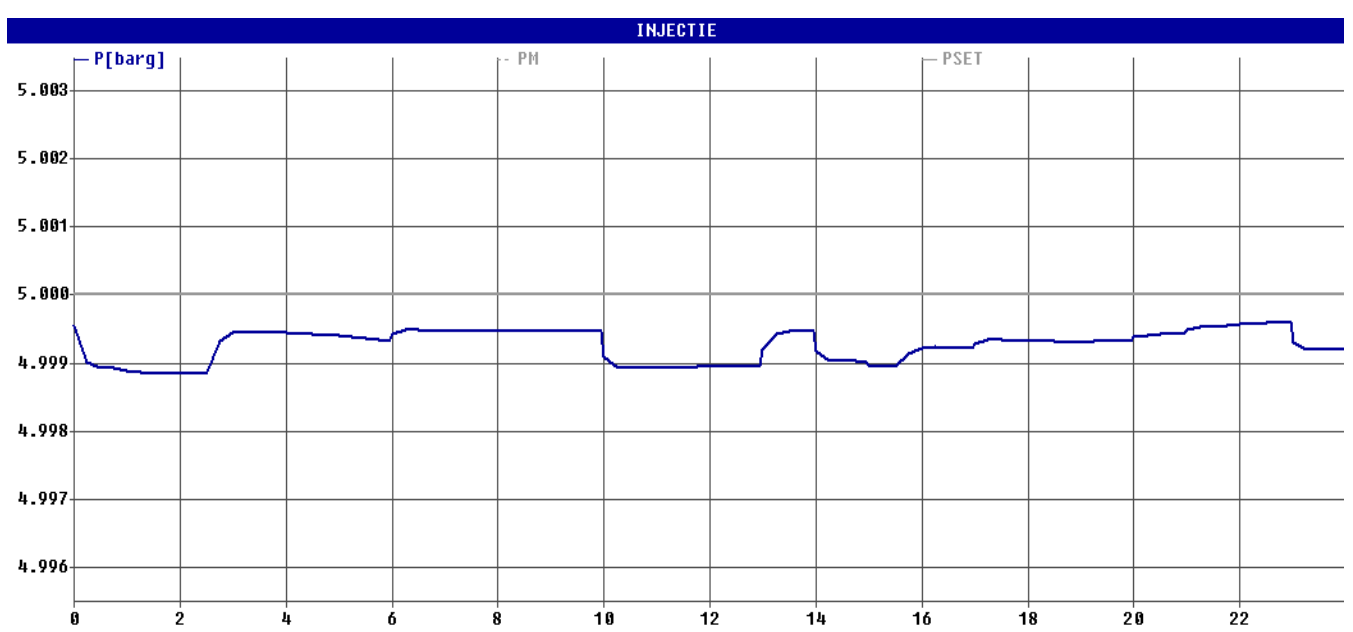

Fig. 4 The variation of the intake pressure in the proposed scenario

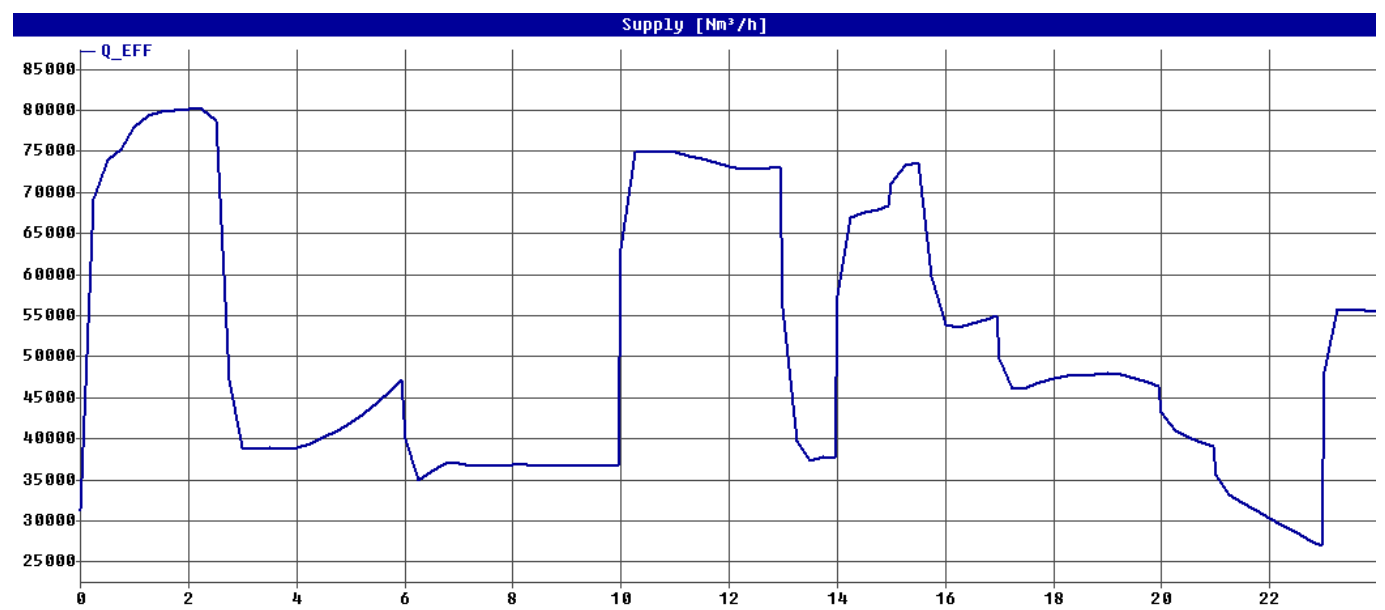

Fig.5 The variation of injection flow in the proposed scenario

Figures 6 and 7 present the variations of pressure and flow at the Consumer. The output of the system follows the consumption profile. The starting quest was the one of the two consumption peaks which can be observed in Fig. 7.

In order to compensate/ balance the peak demands, the regulator opens/starts when needed and uses the gas from the pipe storage. The operation mode of the regulator is shown in Figure 8 . The pressure values before and after the regulator are shown in Fig. 9. The gray color represents the gas pressure before the regulator (in the storage pipe) and the blue color represents the pressure after the regulator. 


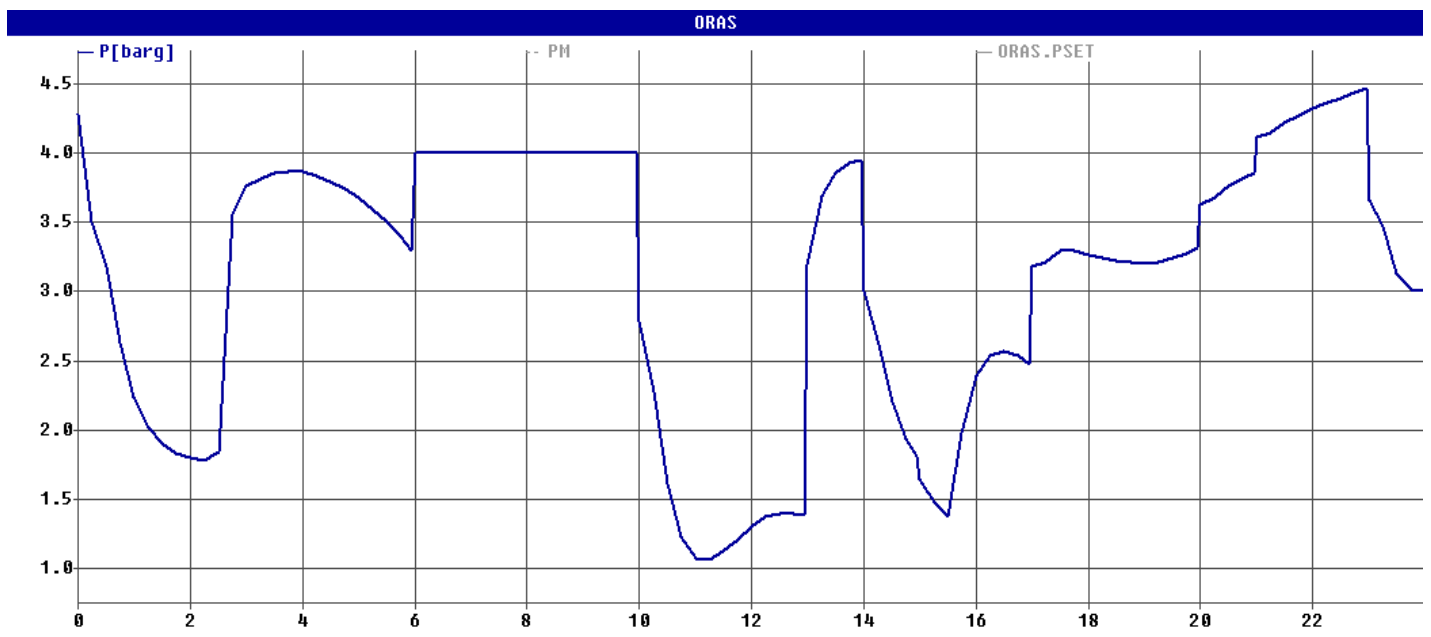

Fig.6 The variation of pressure at the Consumer

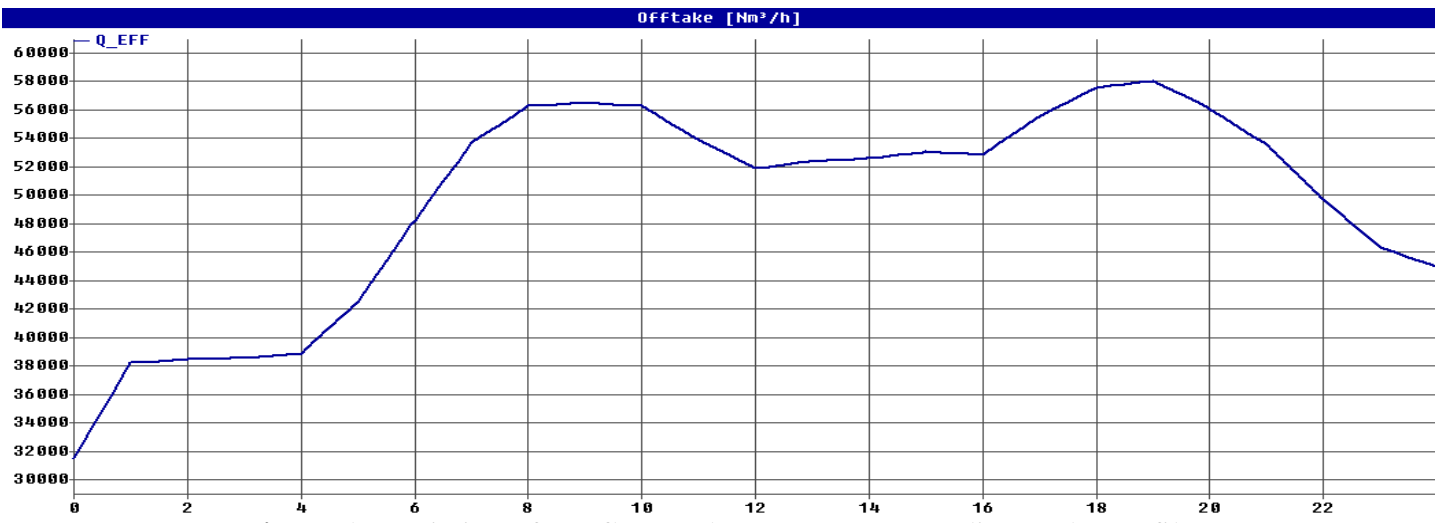

Fig. 7 The variation of gas flow at the Consumer according to the profile

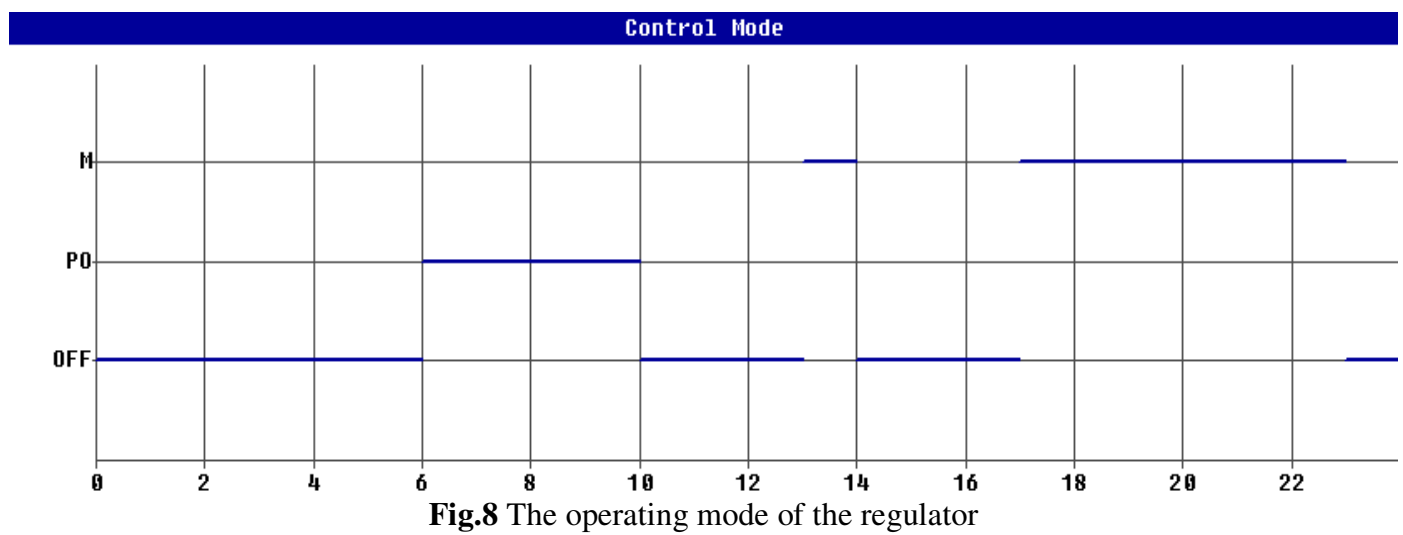




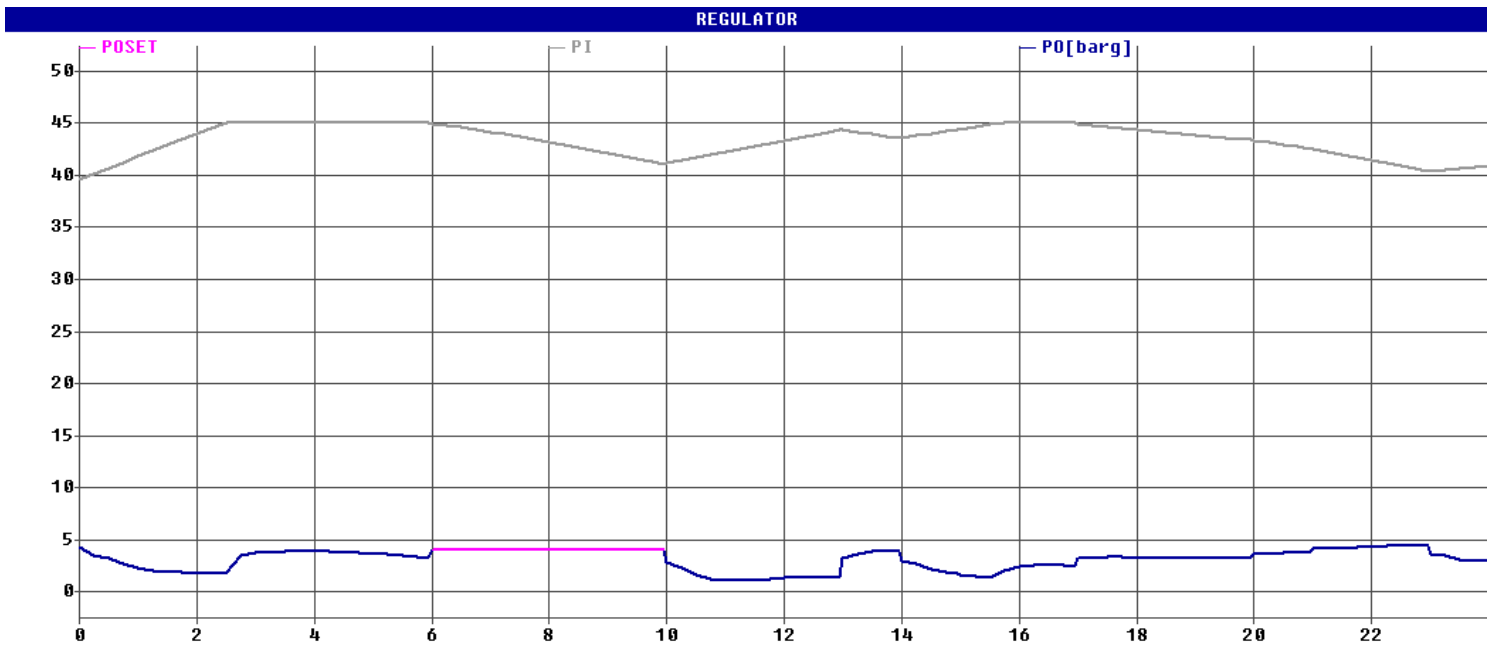

Fig.9 Variation of the pressure before and after the regulator

The gas yields/flows extracted from the pipeline can be seen in Fig. 10 (red is the color for disposed boundaries), and Fig. 11 presents the rates of the gas through the pressure-controller/ regulator.

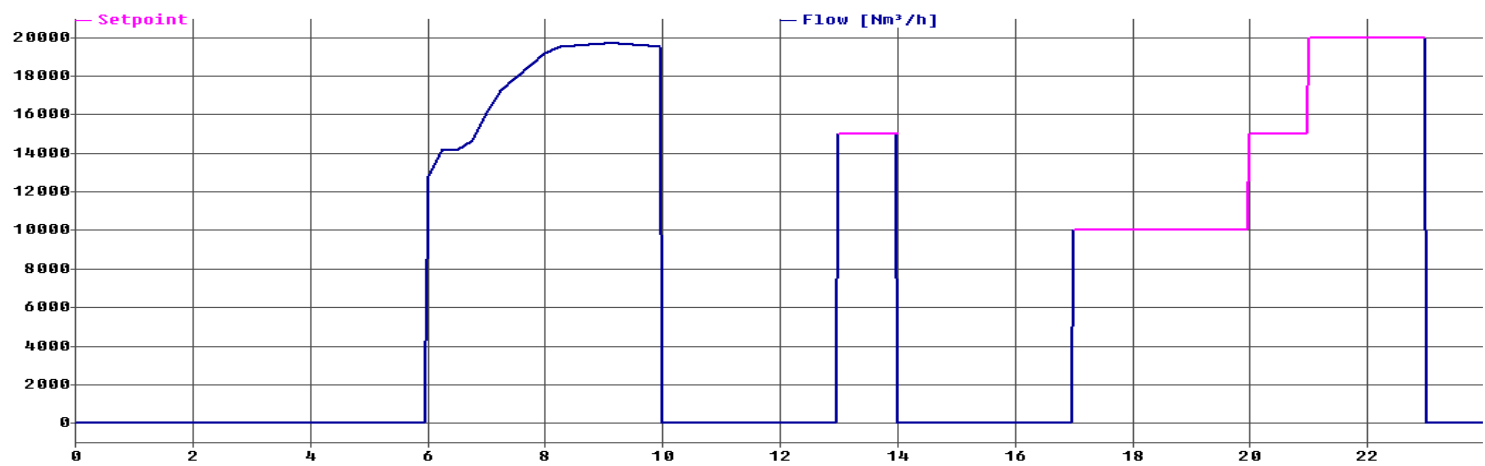

Fig.10 The variation of the gas flow when passing through the regulator

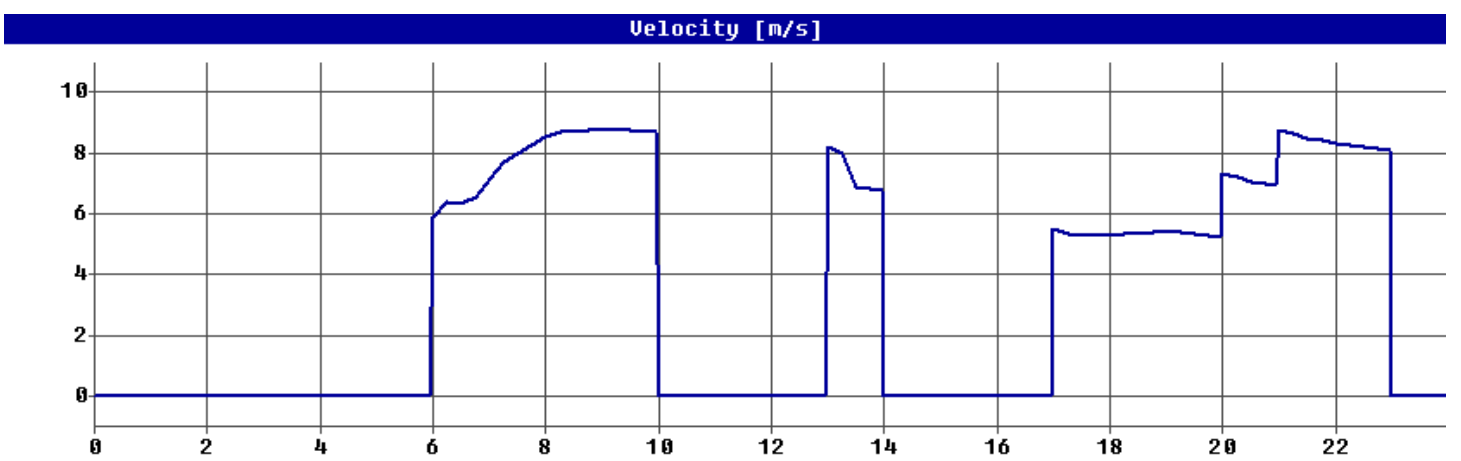

Fig.11 The variation of the flow rate through the regulator 
When the gas flow used in the town is small, the gas can be stored using a reduction plant. Therefore, its operating mode will be intermittent. The operation mode of the plant is shown in Fig. 12, and the variation of suction and discharge / lifting pressure of the compressor is shown in Fig. 13.

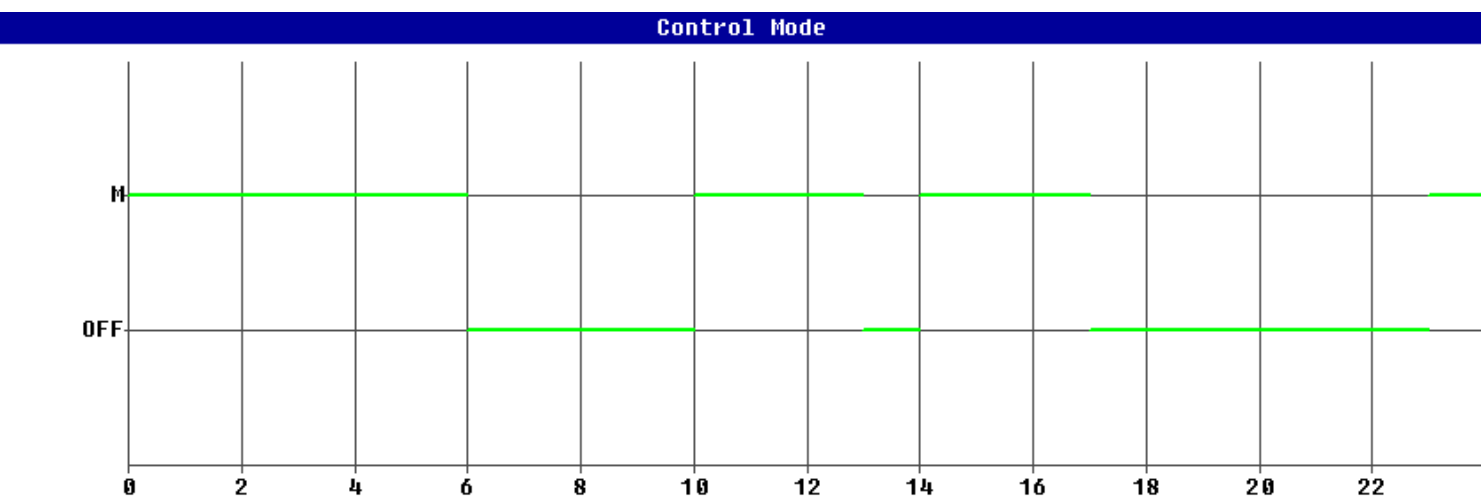

Fig.12 Operation mode of the reduction plant

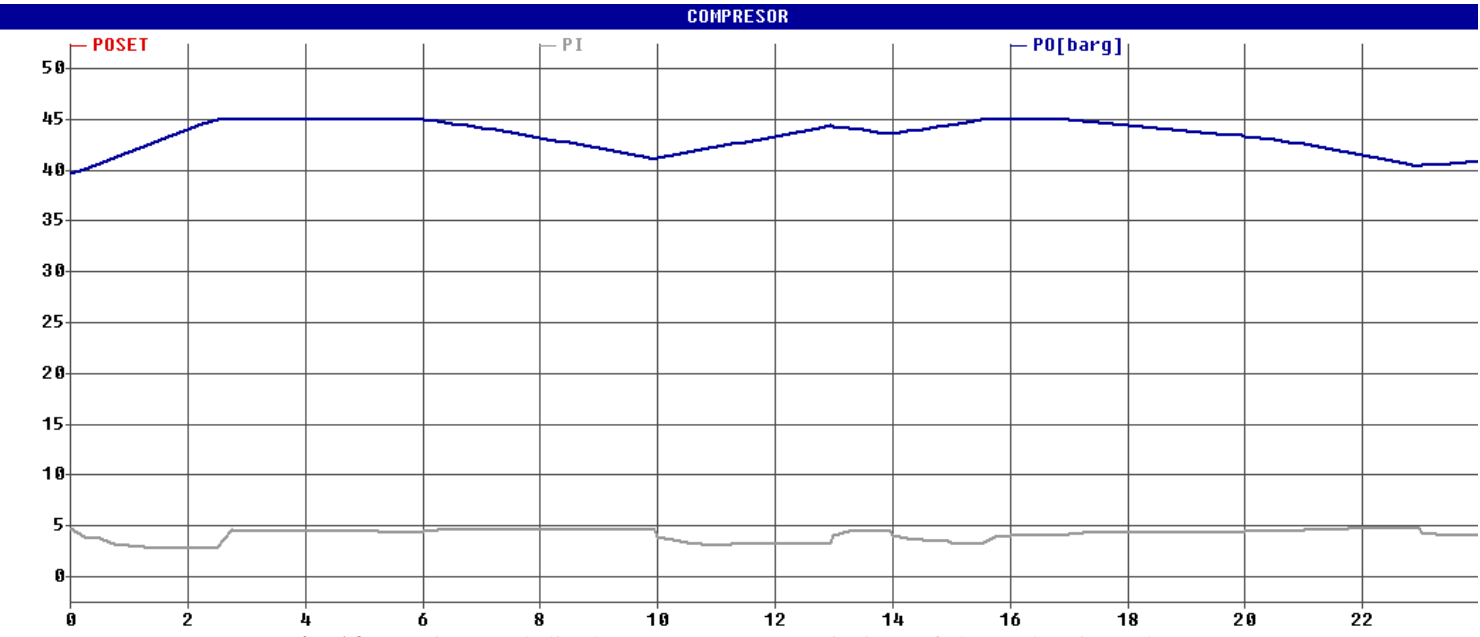

Fig.13 Suction and discharge pressure variation of the reduction plant

Fig. 14 presents the compressed gas flow. It can be observed that although between 3 and 4 o' clock, respectively 4 and 6 o'clock 6 it was supposed to store $40,000 \mathrm{Nm}^{3} / \mathrm{h}$, respectively $45000 \mathrm{Nm}^{3} / \mathrm{h}$ (red line) because the storage pipeline had reached a maximum pressure, the station/ plant stopped. The same thing happens between the 15 and 17 p.m. 


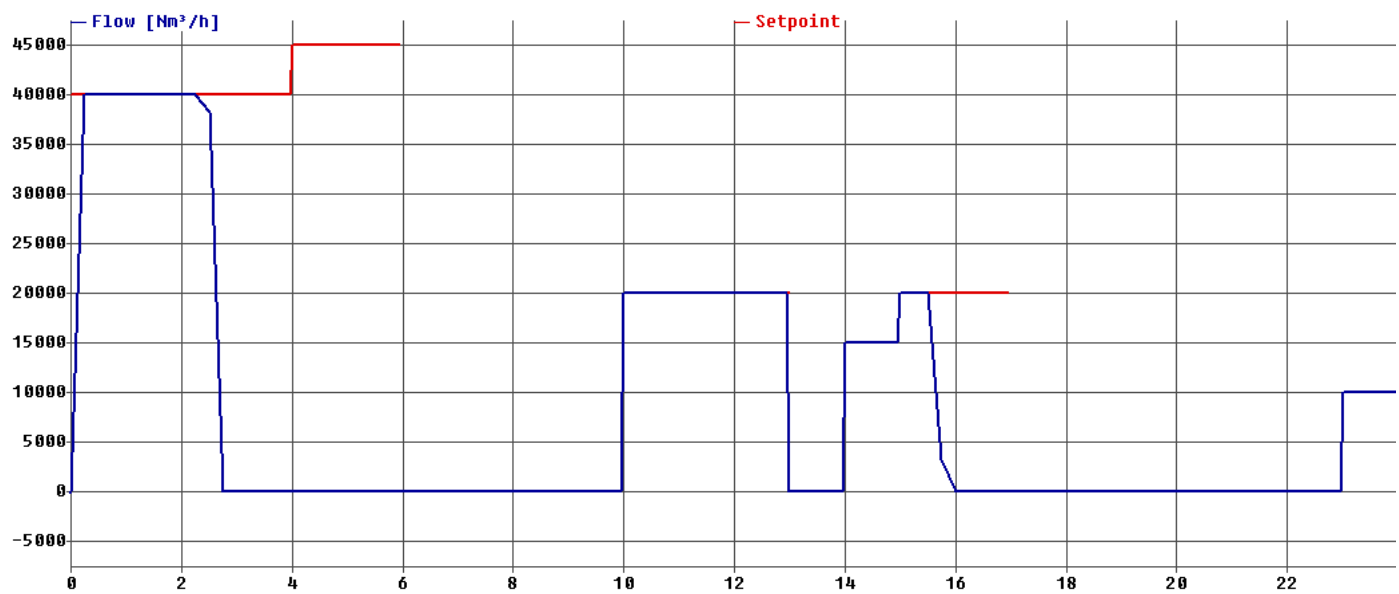

Fig.14 The variation of the reduction plant's flow

The following, are some graphics specific for the reduction plant. Figure 15 shows the changes in the compression ratio, Fig. 16 presents the necessary power and Fig. 17 the amount of fuel consumed by the reduction plant.

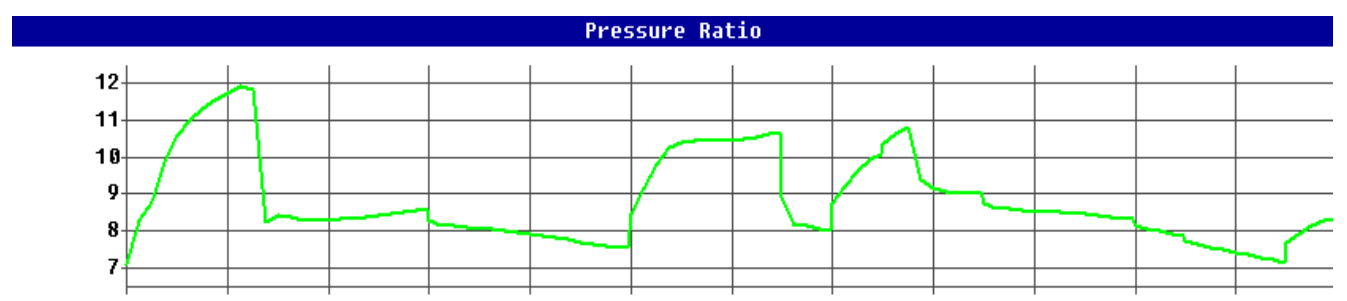

Fig. 15 The variation of reduction plant ratio

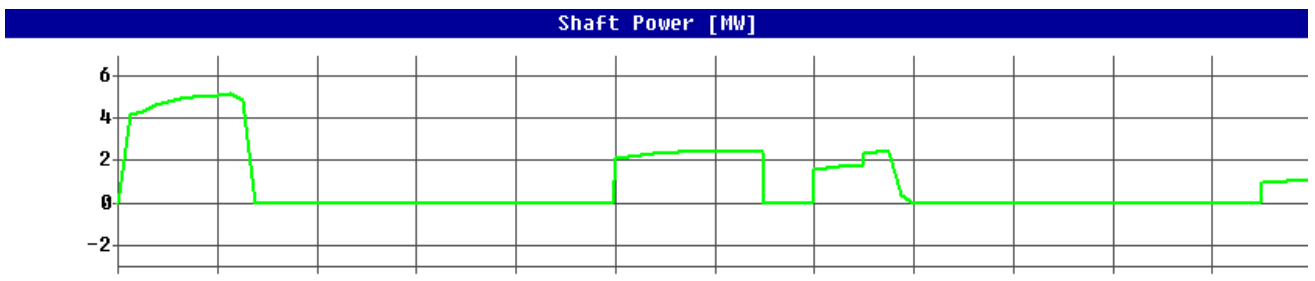

Fig.16 The variation of power for the reduction plant

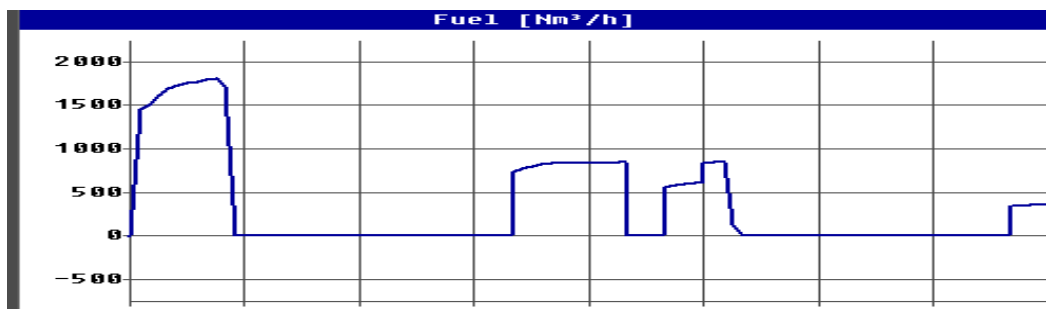

Fig.17 The variation of fuel consumption of the reduction plant 
To have a complete picture of the process there are presented some aspects concerning the storage pipe.
Thus, Fig. 18, 19 and 20 present the pressure, intake gas flow and the flow rate inside the pipe.
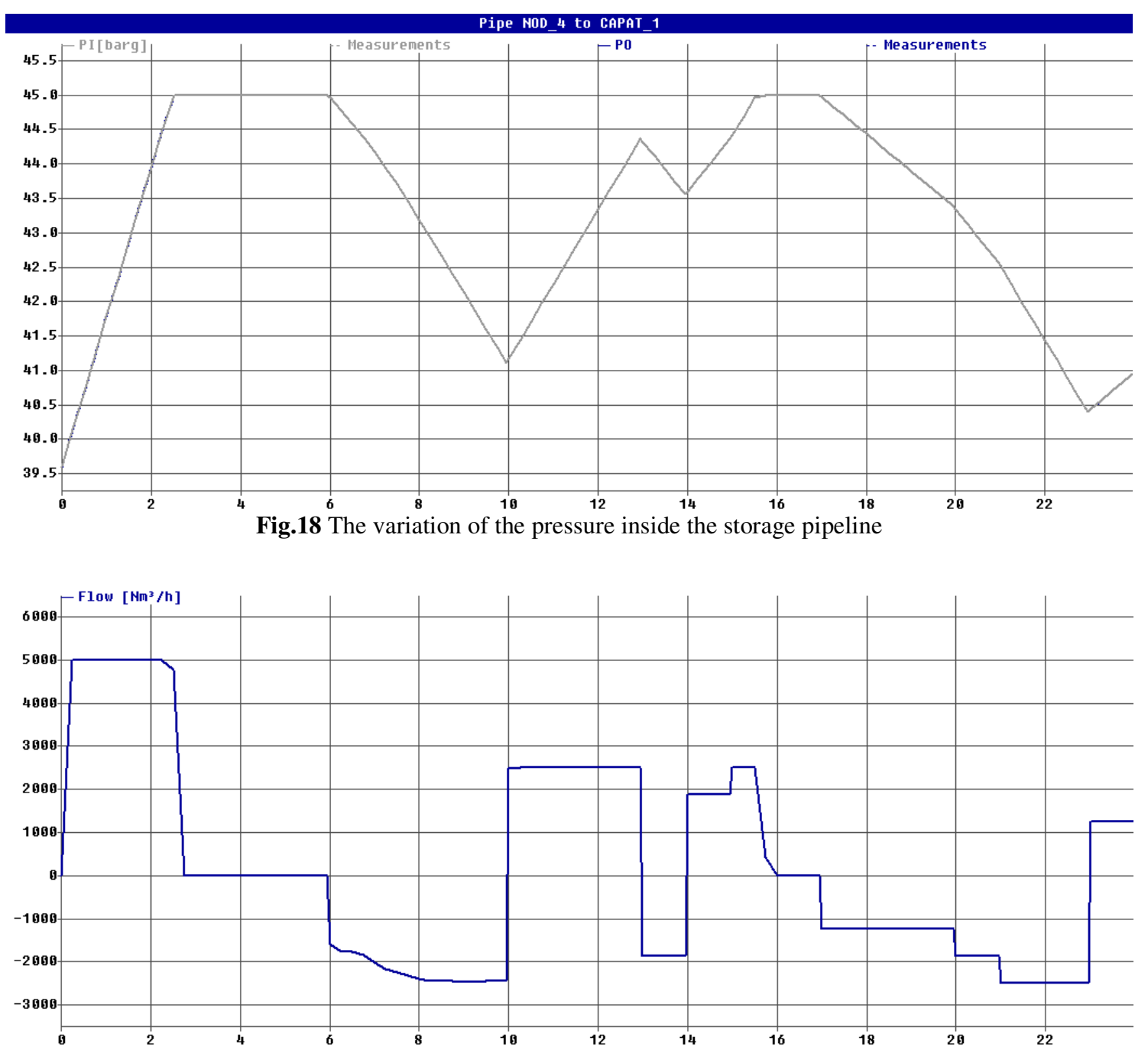

Fig. 19 The variation of gas flow inside the storage pipeline 


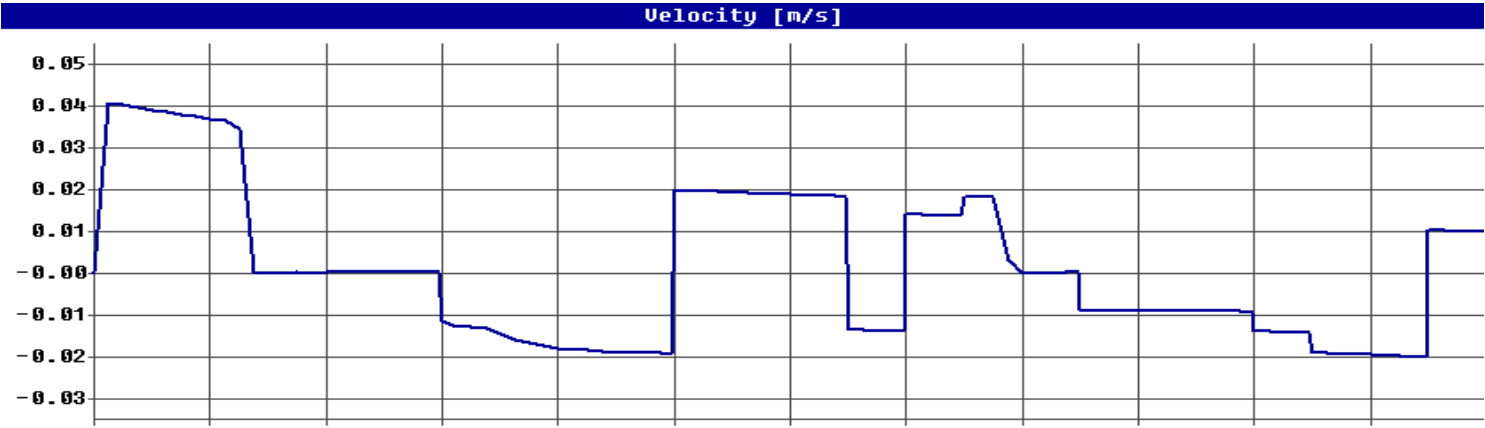

Fig. 20 The variation of flow rate within the storage pipeline

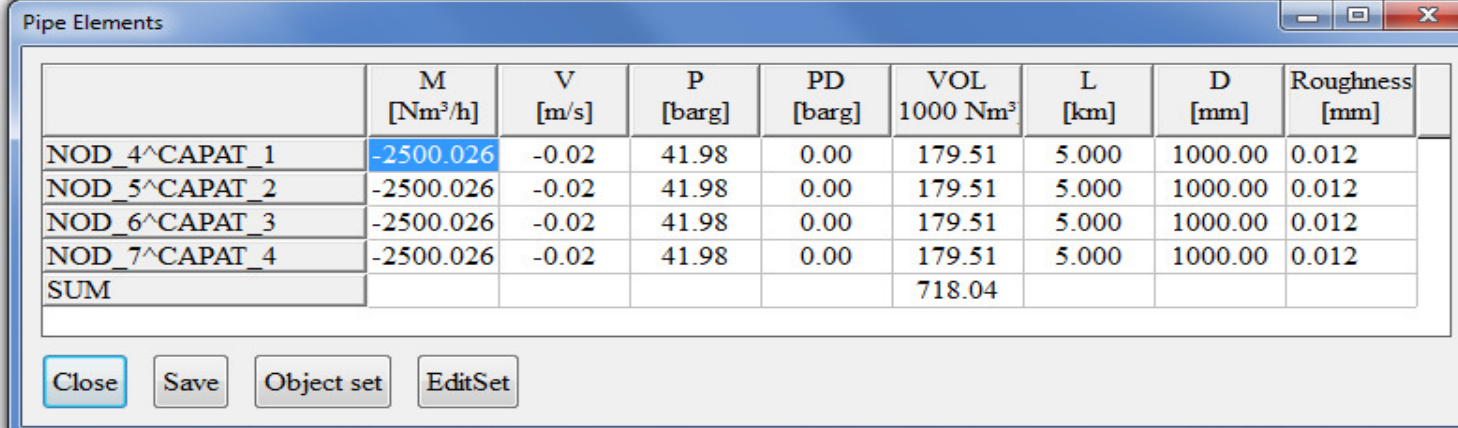

Fig. 21 The variation of the parameters for the pipes constituting the storage pipeline at 21:30

Fig. 21 presents a summary for the storage pipe at a certain time. One can see the amount of gas stored at 21:30 $\left(718,040 \mathrm{Nm}^{3}\right)$.

Since storage pipe is used to offset/ balance the peak demands ( consumption peaks ), its parameters (pressure, stored capacity etc.) will change every time you extract gas from the pipe or when the reduction plant is started in order to restore the pressure. It was therefore considered necessary to present the variation of gas volume stored in the pipe (Fig.22).

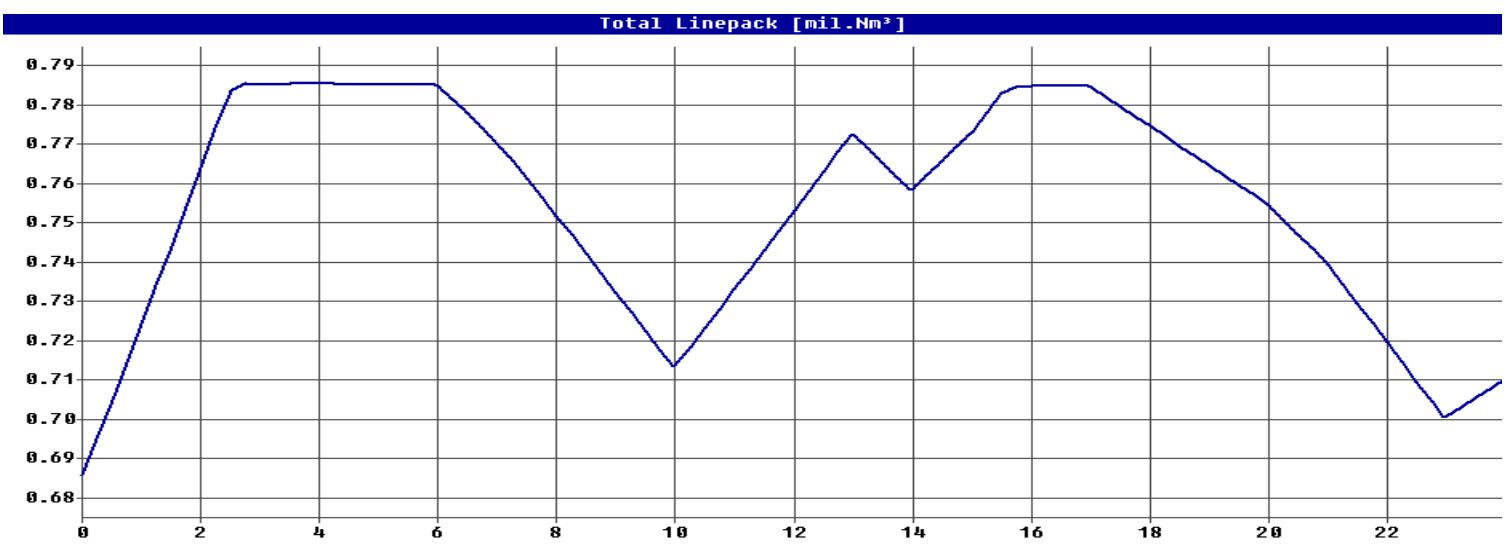

Fig. 22The variation of gas volume in the storage pipeline 


\section{Conclusions}

The advantage of using the gas storage system in the pipes to cover peak loads consists in balancing the forecast consumption and the real consumption in order to eliminate penalties.

Currently in-pipe storage pressures in Romania are 40bar, but in the future the storage pressures may increase up to 70 bar.

This system of gas storage in the pipe, during exploitation, requires a relatively low gas flow, used to balance the peak loads. For this reason, as it is shown in the model, the reduction plant is operating intermittently, as needed. During the day it works only a few hours, usually after over-passing the peak load.

\section{References}

Email address: cristian.eparu@gmail.com

[1]. Neacsu, S., Gas Compression and Liquefaction (in Romanian), Romconvert Publishing House, Ploiesti, 2002

[2]. Neacşu, S., Thermotechnics and Thermal Machines (in Romanian), Printech Publishing House, Bucureşti, 2009

[3]. Trifan, C., Albulescu, M., Neacşu, S., Fluid Mechanics and Technical Thermodynamics (in Romanian), Petroleum-Gas University Publishing House, 2005, Ploieşti.
[4]. Stošić, N., Smith, I.K., Kovacevic, A., Screw Compressors - Mathematical Modeling and Performance Calculation. Springer-Verlag Berlin Heidelberg, 2005.

[5]. Ø. Arvesen, V. Medbø, S.-E. Fleten, A. Tomasgard, S. Westgaard, Linepack storage valuation under price uncertainty, Energy, Volume 52, 1, 2013, 155-164

[6]. J. Villada, Yris Olaya, A simulation approach for analysis of short-term security of natural gas supply in Colombia, Energy Policy, Volume 53, 2013, 11-26

[7]. *** GTE comments on ERGEG "Gas Balancing” Discussion Paper (18 July 2005), 30 September 2005

[8]. *** Calculation of Available Capacities: Understanding and Issues - An ERGEG Public Consultation Paper, 14-June-2007

[9]. *** Capacity Allocation on European Gas Transmission Networks, Pilot Framework Guideline, 10 June 2010

[10]. http://www.simone.eu/simone-companyabout.asp

Submitted: May $20^{\text {th }} 2013$ Accepted in revised form: August 20 $0^{\text {th }}, 2013$ 